\title{
Mucilaginibacter kameinonensis sp., nov., isolated from garden soil
}

\author{
Correspondence \\ Michio Sunairi \\ sunairi.michio@nihon-u.ac.jp
}

\author{
Makoto Urai, ${ }^{1} \dagger \ddagger$ Tomoko Aizawa, ${ }^{1} \dagger$ Yasuyoshi Nakagawa, ${ }^{2}$ \\ Mutsuyasu Nakajima ${ }^{1,3}$ and Michio Sunairi ${ }^{1}$
}

\author{
${ }^{1}$ Department of Applied Biological Sciences, College of Bioresource Sciences, Nihon University, \\ 1866 Kameino, Fujisawa, Kanagawa 252-8510, Japan \\ ${ }^{2}$ Biological Resource Center (NBRC), Department of Biotechnology, National Institute of \\ Technology and Evaluation, 2-5-8 Kazusakamatari, Kisarazu, Chiba 292-0818, Japan \\ ${ }^{3}$ Environmental Program, Nihon University Advanced Research Institute for the Sciences and \\ Humanities, 12-5 Goban-cho Chiyoda, Tokyo 102-8251, Japan
}

It has been reported that some bacterial strains belonging to the genus Rhodococcus produce extracellular polysaccharides (EPS), including fatty acids containing EPS, and that these EPS have a variety of functions, including protection of bacterial cells from the toxicity of hydrocarbons (Aizawa et al., 2005; Iwabuchi et al., 2000), emulsification, moisture absorption (Urai et al., 2002, 2004) and stimulation of degradation of polyaromatic hydrocarbons $(\mathrm{PAH})$ spilled in marine environments, the latter probably occurring via stimulation of marine PAHassimilating bacteria (Iwabuchi et al., 2002). These EPS are acidic, high-molecular-mass polysaccharides containing uronic acids (Urai et al., 2006a, b, 2007a, b). During the screening for micro-organisms that were able to assimilate the EPS produced by Rhodococcus rhodochrous S-2 (S-2 EPS), strain $\mathrm{SCK}^{\mathrm{T}}$ was isolated from a soil sample taken

†These authors contributed equally to this work.

łPresent address: RIKEN (The Institute of Physical and Chemical Research), 2-1 Hirosawa, Wako, Saitama 351-0198, Japan.

Abbreviations: EPS, extracellular polysaccharide; $\mathrm{PAH}$, polyaromatic hydrocarbon.

The GenBank/EMBL/DDBJ accession number for the $16 \mathrm{~S}$ rRNA gene sequence of strain $\mathrm{SCK}^{\top}$ is $\mathrm{AB} 330392$. from a garden on our campus at Kameino, Fujisawa, Japan. The strain formed mucoid colonies and produced a large amount of EPS. On the basis of phenotypic, genotypic, chemotaxonomic and phylogenetic analyses, it was concluded that strain $\mathrm{SCK}^{\mathrm{T}}$ was affiliated with the genus Mucilaginibacter and represents a novel species of this genus.

The genus Mucilaginibacter was established recently and belongs to the family Sphingobacteriaceae; it currently includes two species, Mucilaginibacter gracilis and Mucilaginibacter paludis, which were isolated from an acidic Sphagnum peat bog as pectin-, xylan- and laminarindegrading bacteria (Pankratov et al., 2007).

After a series of three enrichments in MU liquid medium $\left[0.2 \mathrm{~g} \mathrm{MgCl}_{2} .7 \mathrm{H}_{2} \mathrm{O}, 0.1 \mathrm{~g} \mathrm{CaCl}_{2} \cdot 2 \mathrm{H}_{2} \mathrm{O}, 0.1 \mathrm{~g} \mathrm{NaCl}, 0.02 \mathrm{~g}\right.$

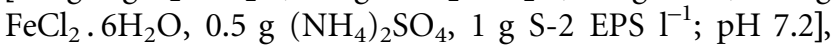
strain $\mathrm{SCK}^{\mathrm{T}}$ was isolated on MU agar plates (solidified with

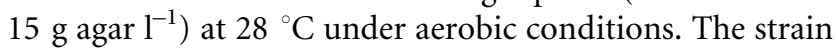
formed mucoid colonies on MU agar plates as well as on tryptic soy agar (TSA) and IB agar (Sunairi et al., 1997) plates but showed little or no growth on MacConkey agar. After cultivation of the strain in IB liquid medium at $28{ }^{\circ} \mathrm{C}$ for 1 week, EPS was detected in the culture supernatant at 
$0.5 \mathrm{~g} \mathrm{l}^{-1}$, which was calculated as $0.7 \mathrm{~g}$ EPS (g dry cells $)^{-1}$. This EPS contained D-galactose, D-glucose, D-mannose and L-rhamnose in equimolar amounts. The chemical structure and functional aspects of the EPS produced by strain SCK will be described elsewhere. The strain showed good growth on TSA at $5-30{ }^{\circ} \mathrm{C}$, with an optimum at $25{ }^{\circ} \mathrm{C}$, but did not grow at $45{ }^{\circ} \mathrm{C}$. Strain $\mathrm{SCK}^{\mathrm{T}}$ showed good growth in tryptic soy broth (TSB) over the $\mathrm{pH}$ range 4-9, with optimum growth at $\mathrm{pH} 5-8$, but showed little or no growth below $\mathrm{pH} 3$ or above $\mathrm{pH} 10$, when grown at $30{ }^{\circ} \mathrm{C}$ for 5 days. The strain showed good growth in the presence of $0.5 \%(\mathrm{w} / \mathrm{v}) \mathrm{NaCl}$ in TSB, but little or no growth occurred in the presence of $1 \%(\mathrm{w} / \mathrm{v}) \mathrm{NaCl}$ or higher. The strain was Gram-negative (Ryu, 1938) and was nonendospore-forming and aerobic. Motility was not observed. Cellular morphology was observed by scanning electron microscopy. After critical-point drying, specimens were sputter-coated with gold and palladium. The cells appeared as irregular rods, $0.3-0.7 \mu \mathrm{m}$ wide and 0.8 $3.5 \mu \mathrm{m}$ long, when the organisms were cultured on IB agar plates at $25{ }^{\circ} \mathrm{C}$ for 2 days (Fig. 1).

The 16S rRNA gene of the strain was amplified by PCR using universal primers (Tamura \& Hatano, 2001), and the nearly complete $16 \mathrm{~S}$ rRNA gene nucleotide sequence (1451 bp) was determined. By sequence match analysis using the Ribosome Database Project II, the sequence of strain $\mathrm{SCK}^{\mathrm{T}}$ showed high similarities to sequences of the type strains of species belonging to the family Sphingobacteriaceae, i.e. the genera Mucilaginibacter, Olivibacter, Parapedobacter, Pedobacter and Sphingobacterium. The highest sequence similarities were found with the type strains of M. gracilis and M. paludis ( $93 \%$ similarity). The $16 \mathrm{~S}$ rRNA gene sequences of all other species of the family Sphingobacteriaceae had $<91 \%$ similarity with that of strain $\mathrm{SCK}^{\mathrm{T}}$. The phylogenetic

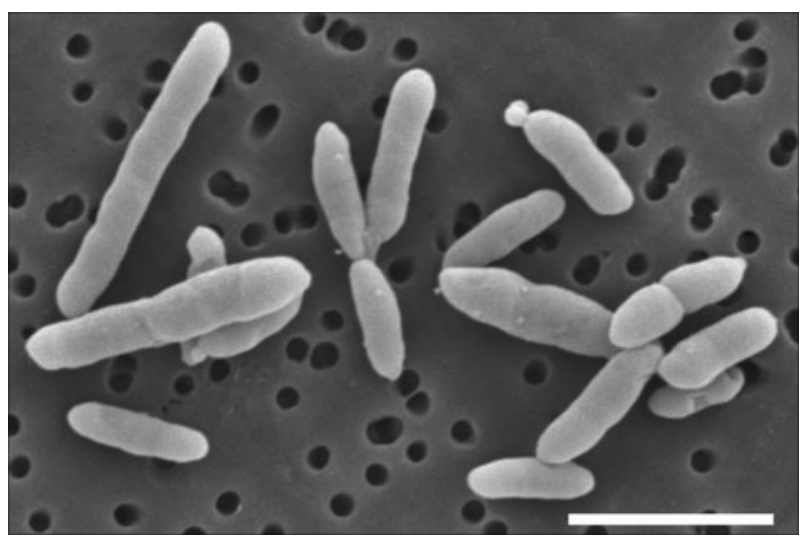

Fig. 1. Scanning electron micrograph of cells of strain $\mathrm{SCK}^{\top}$. Cells were grown on IB agar plates at $25^{\circ} \mathrm{C}$ for 2 days. After critical-point drying, specimens were sputter-coated with gold/ palladium and observed with a scanning electron microscope (S3500N; Hitachi). Bar, $2 \mu \mathrm{m}$. relationship between strain $\mathrm{SCK}^{\mathrm{T}}$ and closely related species was determined by using MEGA version 4 (Tamura et al., 2007) after multiple alignments of the data performed by using CLUSTAL_x (Thompson et al., 1997). Evolutionary distances were computed as described by Jukes \& Cantor (1969). Phylogenetic trees were constructed by using the maximum-parsimony (Kluge \& Farris, 1969) and neighbour-joining (Saitou \& Nei, 1987) methods. The reliabilities of these tree topologies were evaluated by bootstrap analysis with 1000 replicates (Felsenstein, 1985). The phylogenetic trees constructed by the two methods were topologically similar and showed that strain $\mathrm{SCK}^{\mathrm{T}}$ belonged to the genus Mucilaginibacter and formed a separate line of descent in the phylogenetic cluster of the genus (Fig. 2). As pointed out by Stackebrandt \& Goebel (1994), a low degree of $16 \mathrm{~S}$ rRNA gene sequence similarity (below 97\%) is of value for differentiating species, and DNA-DNA hybridization studies are not needed. These data suggest that strain $\mathrm{SCK}^{\mathrm{T}}$ represents a novel species of the genus Mucilaginibacter.

Analyses of menaquinones, DNA G+C content and cellular fatty acids were performed as described previously (Tamura et al., 1994). The major isoprenoid quinone of the strain was MK-7. The DNA G + C content was $43.7 \mathrm{~mol} \%$. The fatty acid profile of strain $\mathrm{SCK}^{\mathrm{T}}(>1.0 \%$ of total fatty acids) included straight-chain fatty acids $\mathrm{C}_{16: 0}(7.6 \%)$, $\mathrm{C}_{14: 0}(2.0 \%)$, and $\mathrm{C}_{15: 0}(1.2 \%)$, branched fatty acids iso$\mathrm{C}_{15: 0}(25.9 \%)$ and iso- $\mathrm{C}_{17: 1} \omega 9 c(1.4 \%)$, summed feature 3 (comprising $\mathrm{C}_{16: 1} \omega 7 c$ and/or iso- $\left.\mathrm{C}_{15: 0} 2-\mathrm{OH}\right)(49.2 \%)$, hydroxy fatty acids iso- $\mathrm{C}_{17: 0} 3-\mathrm{OH}(5.6 \%), \mathrm{C}_{16: 0} 3-\mathrm{OH}$ $(2.7 \%)$ and iso- $\mathrm{C}_{15: 0} 3-\mathrm{OH}(1.1 \%)$ and unsaturated fatty acid $\mathrm{C}_{16: 1} \omega 5 c(3.3 \%)$.

By the bathochromic shift test with $20 \%(\mathrm{w} / \mathrm{v}) \mathrm{KOH}$ (Fautz \& Reichenbach, 1980), flexirubin-type pigments were detected. The long-chain acyl components of cellular sphingolipids were analysed as described previously (Yano et al., 1982). Strain $\mathrm{SCK}^{\mathrm{T}}$ contained sphingolipids with d-17:0 as the main dihydrosphingosine.

Standard physiological tests were carried out according to the methods of Smibert \& Krieg (1994). Acid production from carbon sources was assessed by using the API $50 \mathrm{CH}$ system and enzyme activities with the API $20 \mathrm{E}$ and API ZYM systems according to the manufacturer's instructions (bioMérieux) (incubation times of up to 7 days). Oxidation of various substrates was tested using Biolog GN2 Microplates (Biolog) in accordance with the manufacturer's instructions. Heparinase activity was tested according to Zimmermann et al. (1990). Strain SCK ${ }^{\mathrm{T}}$ could be distinguished from the other species of Mucilaginibacter on the basis of physiological characteristics (Table 1). Resistance to antibiotics was examined by using the API VET system (bioMérieux) in accordance with the manufacturer's instructions.

Based on phenotypic and phylogenetic characterization, strain $\mathrm{SCK}^{\mathrm{T}}$ was concluded to represent a novel species, for which the name Mucilaginibacter kameinonensis sp. nov. is 


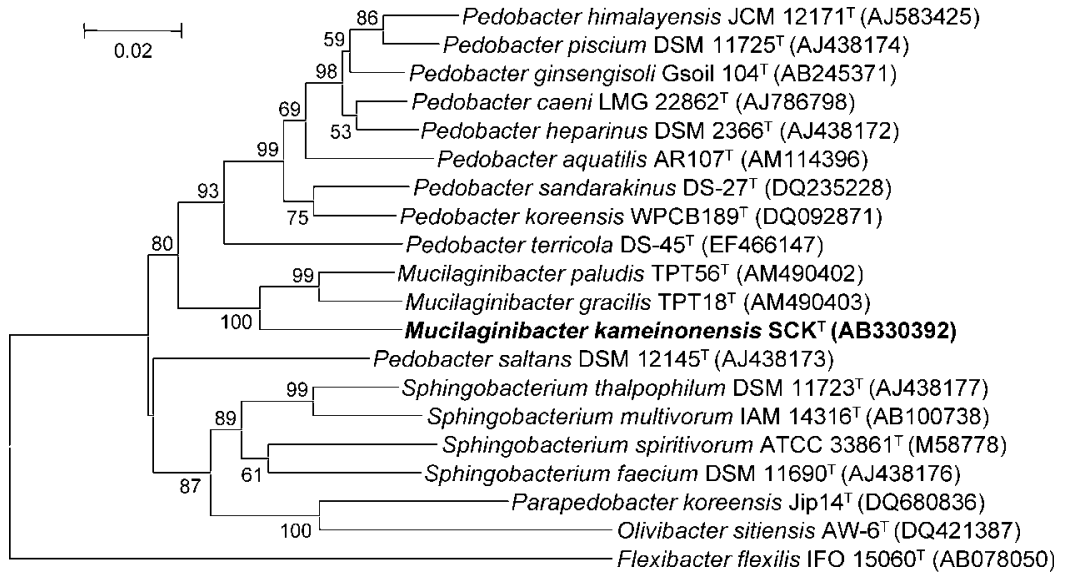

Fig. 2. Neighbour-joining tree (Saitou \& Nei, 1987) based on nearly complete $16 S$ rRNA gene sequences (positions 56-1396 of the Escherichia coli 16S rRNA gene), showing the position of the strain $\mathrm{SCK}^{\top}$ among its phylogenetic neighbours. Numbers at branch nodes are percentages of bootstrap support based on 1000 resamplings; only values over $50 \%$ are given. The sequence of Flexibacter flexilis IFO $15060^{\top}$ was used as an outgroup. Bar, 0.02 substitutions per nucleotide position. proposed. As some properties of strain $\mathrm{SCK}^{\mathrm{T}}$ are not compatible with the original description of the genus Mucilaginibacter (Pankratov et al., 2007), an emended description of the genus is also given.

\section{Emended description of the genus Mucilaginibacter Pankratov et al. 2007}

In contrast to the genus description given by Pankratov et al. (2007), this study shows that strains belonging to the genus Mucilaginibacter are variable for the presence of flexirubintype pigments, oxidase and the utilization of melibiose.

\section{Description of Mucilaginibacter kameinonensis sp. nov.}

Mucilaginibacter kameinonensis (ka.me.i.no.nen'sis. N.L. masc. adj. kameinonensis pertaining to Kameino, the location from which the organism was first isolated).

Gram-negative, non-endospore-forming, non-motile, aerobic, irregular rods, $0.3-0.7 \mu \mathrm{m}$ wide and $0.8-3.5 \mu \mathrm{m}$ long. Growth occurs on TSA and IB agar, but not on MacConkey agar. Colonies are pale pink, mucoid, convex and round with entire margins on TSA and IB agar. Growth occurs between 5 and $30{ }^{\circ} \mathrm{C}$ with an optimum at $25{ }^{\circ} \mathrm{C}$. The $\mathrm{pH}$ range for growth is $\mathrm{pH} 4-9$, with optimum growth at $\mathrm{pH} 5-8$. Growth occurs in the absence of $\mathrm{NaCl}$ and in the presence of $0.5 \%(\mathrm{w} / \mathrm{v}) \mathrm{NaCl}$, but not in the presence of $1 \%(\mathrm{w} / \mathrm{v}) \mathrm{NaCl}$ or higher. Positive for hydrolysis of aesculin and Tweens 20 and 60, but negative for casein and Tweens 40 and 80 . Positive for activities of $N$-acetyl- $\beta$ glucosaminidase, acid and alkaline phosphatases, catalase, cystine arylamidase, DNase, esterase (C4), esterase lipase (C8), $\alpha$-fucosidase, $\alpha$-galactosidase, $\beta$-galactosidase, gelatinase, $\alpha$-glucosidase, $\beta$-glucosidase, $\beta$-glucuronidase, leucine arylamidase, $\alpha$-mannosidase, naphthol-AS-BIphosphohydrolase, trypsin and valine arylamidase, but negative for activities of arginine dihydrolase, $\alpha$-chymotrypsin, heparinase, lipase (C14), lysine decarboxylase, ornithine decarboxylase, oxidase, tryptophan deaminase and urease, as determined with the API ZYM system.
Positive for the Voges-Proskauer test, but negative for hydrogen sulphide and indole production and nitrate reduction. Positive for acid production from $\mathrm{N}$-acetylglucosamine, amygdalin, D- and L-arabinose, cellobiose, aesculin, D-fructose, L-fucose, D-galactose, gentiobiose, Dglucose, glycogen, inulin, D-lactose, maltose, D-mannose, melezitose, melibiose, methyl $\beta$-D-xylopyranoside, potassium 5-ketogluconate, raffinose, salicin, starch, sucrose, trehalose, turanose and D-xylose, but negative for acid production from D-adonitol, D- and L-arabitol, arbutin, dulcitol, erythritol, D-fucose, glycerol, inositol, D-lyxose, Dmannitol, methyl $\alpha$-D-glucopyranoside, methyl $\alpha$-D-mannopyranoside, potassium gluconate, potassium 2-ketogluconate, L-rhamnose, D-ribose, D-sorbitol, L-sorbose, Dtagatose, xylitol and L-xylose, as determined with the API $50 \mathrm{CH}$ system. Positive for Biolog GN2 MicroPlate substrates cellobiose, $\alpha$-cyclodextrin, dextrin, D-fructose, D-galactose, gentiobiose, $\alpha$-D-glucose, glycerol, glycogen, lactulose, maltose, D-mannose, melibiose, methyl $\beta$-Dglucoside, L-proline, raffinose, sucrose, trehalose and turanose, but negative for acetic acid, $\mathrm{N}$-acetyl-D-galactosamine, cis-aconitic acid, adonitol, L-alaninamide, D- and L-alanine, L-alanylglycine, $\gamma$-aminobutyric acid, 2 -aminoethanol, L-arabinose, D-arabitol, L-asparagine, L-aspartic acid, bromosuccinic acid, 2,3-butanediol, D- and Lcarnitine, citrate, i-erythritol, formic acid, L-fucose, Dgalactonic acid lactone, D-galacturonic acid, D-gluconic acid, D-glucosaminic acid, $\alpha$-D-glucose 1-phosphate, Dglucose 6-phosphate, glucuronamide, D-glucuronic acid, Lglutamic acid, D- and L- $\alpha$-glycerol phosphate, glycyl Laspartic acid, glycyl L-glutamic acid, L-histidine, $\alpha-, \beta$ - and $\gamma$-hydroxybutyric acids, $p$-hydroxyphenylacetic acid, hydroxy-L-proline, inosine, myo-inositol, itaconic acid, $\alpha$ ketobutyric acid, $\alpha$-ketoglutaric acid, $\alpha$-ketovaleric acid, Dand L-lactic acid, L-leucine, malate, D-mannitol, Lornithine, L-phenylalanine, phenylethylamine, propionic acid, D-psicose, putrescine, L-pyroglutamic acid, pyruvic acid methyl ester, quinic acid, D-saccharic acid, sebacic acid, D- and L-serine, D-sorbitol, succinamic acid, succinic acid, succinic acid monomethyl ester, L-threonine, thymidine, Tweens 40 and 80, uridine, urocanic acid and xylitol. 
Table 1. Physiological characteristics of strain $\mathrm{SCK}^{\top}$ and type strains of Mucilaginibacter species

Data for M. paludis and M. gracilis were taken from Pankratov et al. (2007). +, Positive; -, negative; w, weakly positive. All strains had the following characteristics: positive for assimilation of cellobiose, Dfructose, D-galactose, D-glucose, D-lactose, maltose, sucrose and trehalose; positive for acid production from cellobiose, D-fructose, D-galactose, D-glucose, maltose, sucrose and D-xylose; positive for catalase activity; negative for assimilation of acetic acid, adonitol, Darabitol, citric acid, malic acid, D-mannitol, propionic acid, D-sorbitol and succinic acid; negative for Gram stain, motility, $\mathrm{H}_{2} \mathrm{~S}$ production, indole production and heparinase activity.

\begin{tabular}{|lccc|}
\hline Characteristic & $\begin{array}{c}\text { Strain } \\
\text { SCK }^{\mathbf{T}}\end{array}$ & $\begin{array}{c}\text { M. paludis } \\
\text { TPT56 }\end{array}$ & $\begin{array}{c}\text { M. } \text { gracilis }^{\mathbf{T}} \\
\text { TPT18 }^{\mathbf{T}}\end{array}$ \\
\hline Ranges for growth & & & \\
Temperature $\left({ }^{\circ} \mathrm{C}\right)$ & $5-30$ & $2-33$ & $2-33$ \\
pH & $4-9$ & $4.2-8.2$ & $4.2-8.2$ \\
DNA G+C content & 43.7 & 46.1 & 42.4 \\
(mol\%) & & & \\
Quinone(s) & MK-7 & MK-7, MK-6 & MK-7, MK-6 \\
Flexirubin pigments & + & - & - \\
Oxidase activity & - & + & + \\
Hydrolysis of aesculin & + & - & - \\
Acid production from: & & & - \\
D-Mannose & + & + & - \\
Melezitose & + & - & - \\
Melibiose & + & - & - \\
Trehalose & + & - & - \\
Assimilation of: & & & - \\
D-Galacturonic acid & - & + & - \\
D-Gluconic acid & - & + & - \\
D-Mannose & + & + & - \\
Melibiose & + & - & - \\
Raffinose & + & - & - \\
myo-Inositol & - & + & - \\
N-Acetyl-D- & W & + & - \\
glucosamine & & & - \\
& & & \\
\hline
\end{tabular}

Resistant to apramycin, cefoperazone, cephalothin, chloramphenicol, colistin, enrofloxacin, erythromycin, flumequine, gentamicin, kanamycin, lincomycin, metronidazole, nitrofurantoin, oxacillin, oxolinic acid, penicillin, rifampicin and streptomycin, but sensitive to amoxicillin, augmentin, cotrimoxazole, doxycycline, fusidic acid, pristinamycin, spectinomycin, sulphamethizole, tetracycline and tylosin (API VET system). The major isoprenoid quinone is MK-7 and the major fatty acids ( $>10 \%$ of total fatty acids) are iso- $\mathrm{C}_{15: 0}(25.9 \%)$ and summed feature 3 $\left(\mathrm{C}_{16: 1} \omega 7 c\right.$ and/or iso- $\left.\mathrm{C}_{15: 0} 2-\mathrm{OH}\right)(49.2 \%)$. Sphingolipids are present, with $\mathrm{d}-17: 0$ as the main dihydrosphingosine. Flexirubin-type pigments are present. The DNA G+C content of the type strain is $43.7 \mathrm{~mol} \%$.

The type strain, SCK ${ }^{\mathrm{T}}\left(=\mathrm{NBRC} 102645^{\mathrm{T}}=\right.$ KCTC $\left.22227^{\mathrm{T}}\right)$, was isolated from a soil sample from the campus of the College of Bioresource Sciences, Nihon University, at Kameino, Fujisawa, Kanagawa, Japan.

\section{Acknowledgements}

We are grateful to T. Tamura at the NBRC and K. Ueda at the Life Science Center for use of their instrumental facilities. We acknowledge N. Iwabuchi, M. Suzuki, K. Shimoda, A. Takahashi and various members of our laboratories for their technical assistance and encouragement. We also recognize N. Akimoto, M. Hyoudou, M. Kogure and N. Sekino at the Integrated Research Institute for their technical assistance. M. U. and T. A. were supported by funding from the Center of Excellence in 21st Century Projects of the Ministry of Education, Culture, Sports, Science, and Technology of Japan.

\section{References}

Aizawa, T., Neilan, A. B., Couperwhite, I., Urai, M., Anzai, H., Iwabuchi, N., Nakajima, M. \& Sunairi, M. (2005). Relationship between extracellular polysaccharide and benzene tolerance of Rhodococcus sp. 33. Actinomycetologica 19, 1-6.

Fautz, E. \& Reichenbach, H. (1980). A simple test for flexirubin-type pigments. FEMS Microbiol Lett 8, 87-91.

Felsenstein, J. (1985). Confidence limits on phylogenies: an approach using the bootstrap. Evolution 39, 783-791.

Iwabuchi, N., Sunairi, M., Anzai, H., Nakajima, M. \& Harayama, S. (2000). Relationships between colony morphotypes and oil tolerance in Rhodococcus rhodochrous. Appl Environ Microbiol 66, 5073-5077.

Iwabuchi, N., Sunairi, M., Urai, M., Itoh, C., Anzai, H., Nakajima, M. \& Harayama, S. (2002). Extracellular polysaccharides of Rhodococcus rhodochrous S-2 stimulate the degradation of aromatic components in crude oil by indigenous marine bacteria. Appl Environ Microbiol 68, 2337-2343.

Jukes, T. H. \& Cantor, C. R. (1969). Evolution of protein molecules. In Mammalian Protein Metabolism, vol. 3, pp. 21-132. Edited by H. N. Munro. New York: Academic Press.

Kluge, A. G. \& Farris, F. S. (1969). Quantitative phyletics and the evolution of anurans. Syst Zool 18, 1-32.

Pankratov, T. A., Tindall, B. J., Liesack, W. \& Dedysh, S. N. (2007). Mucilaginibacter paludis gen. nov., sp. nov. and Mucilaginibacter gracilis sp. nov., pectin-, xylan- and laminarin-degrading members of the family Sphingobacteriaceae from acidic Sphagnum peat bog. Int $J$ Syst Evol Microbiol 57, 2349-2354.

Ryu, E. (1938). On the Gram-differentiation of bacteria by the simplest method. J Jpn Soc Vet Sci 17, 31.

Saitou, N. \& Nei, M. (1987). The neighbor-joining method: a new method for reconstructing phylogenetic trees. Mol Biol Evol 4, 406-425.

Smibert, R. M. \& Krieg, N. R. (1994). Phenotypic characterization. In Methods for General and Molecular Bacteriology, pp. 607-654. Edited by P. Gerhardt, R. G. E. Murray, W. A. Wood \& N. R. Krieg. Washington, DC: American Society for Microbiology.

Stackebrandt, E. \& Goebel, B. M. (1994). Taxonomic note: a place for DNA-DNA reassociation and 16S rRNA sequence analysis in the present species definition in bacteriology. Int J Syst Bacteriol 44, 846849.

Sunairi, M., Iwabuchi, N., Yoshizawa, Y., Murooka, H., Morisaki, H. \& Nakajima, M. (1997). Cell-surface hydrophobicity and scum formation of Rhodococcus rhodochrous strains with different colonial morphologies. J Appl Microbiol 82, 204-210.

Tamura, T. \& Hatano, K. (2001). Phylogenetic analysis of the genus Actinoplanes and transfer of Actinoplanes minutisporangius Ruan et al. 1986 and 'Actinoplanes aurantiacus' to Cryptosporangium minutisporangium comb. nov. and Cryptosporangium aurantiacum sp. nov. Int J Syst Evol Microbiol 51, 2119-2125. 
Tamura, T., Nakagaito, Y., Nishii, T., Hasegawa, T., Stackebrandt, E. \& Yokota, A. (1994). A new genus of the order Actinomycetales, Couchioplanes gen. nov., with descriptions of Couchioplanes caeruleus (Horan and Brodsky 1986) comb. nov. and Couchioplanes caeruleus subsp. azureus subsp. nov. Int J Syst Bacteriol 44, 193-203.

Tamura, K., Dudley, J., Nei, M. \& Kumar, S. (2007). MEGA4: molecular evolutionary genetics analysis (MEGA) software version 4.0. Mol Biol Evol 24, 1596-1599.

Thompson, J. D., Gibson, T. J., Plewniak, F., Jeanmougin, F. \& Higgins, D. G. (1997). The CLUSTAL_X windows interface: flexible strategies for multiple sequence alignment aided by quality analysis tools. Nucleic Acids Res 25, 4876-4882.

Urai, M., Anzai, H., Iwabuchi, N., Sunairi, M. \& Nakajima, M. (2002). A novel moisture-absorbing extracellular polysaccharide from Rhodococcus rhodochrous SM-1. Actinomycetologica 16, 26-31.

Urai, M., Anzai, H., Iwabuchi, N., Sunairi, M. \& Nakajima, M. (2004). A novel viscous extracellular polysaccharide containing fatty acids from Rhodococcus rhodochrous ATCC 53968. Actinomycetologica 18, 15-17.

Urai, M., Aizawa, T., Anzai, H., Ogihara, J., Iwabuchi, N., Neilan, B., Couperwhite, I., Nakajima, M. \& Sunairi, M. (2006a). Structural analysis of an extracellular polysaccharide produced by a benzene tolerant bacterium, Rhodococcus sp. 33. Carbohydr Res 341, 616-623.

Urai, M., Anzai, H., Ogihara, J., Iwabuchi, N., Harayama, S., Sunairi, M. \& Nakajima, M. (2006b). Structural analysis of an extracellular polysaccharide produced by Rhodococcus rhodochrous strain S-2. Carbohydr Res 341, 766-775.

Urai, M., Yoshizaki, H., Anzai, H., Ogihara, J., Iwabuchi, N., Harayama, S., Sunairi, M. \& Nakajima, M. (2007a). Structural analysis of mucoidan, an acidic extracellular polysaccharide produced by a pristane-assimilating marine bacterium, Rhodococcus erythropolis PR4. Carbohydr Res 342, 927-932.

Urai, M., Yoshizaki, H., Anzai, H., Ogihara, J., Iwabuchi, N., Harayama, S., Sunairi, M. \& Nakajima, M. (2007b). Structural analysis of an acidic, fatty acid ester-bonded extracellular polysaccharide produced by a pristane-assimilating marine bacterium, Rhodococcus erythropolis PR4. Carbohydr Res 342, 933-942.

Yano, I., Tomiyasu, I. \& Yabuuchi, E. (1982). Long chain base composition of strains of three species of Sphingobacterium gen. nov. FEMS Microbiol Lett 15, 303-307.

Zimmermann, J. J., Langer, R. \& Cooney, C. L. (1990). Specific plate assay for bacterial heparinase. Appl Environ Microbiol 56, 3593-3594. 